\title{
Penyebab dan Solusi Lama Waktu Tunggu Pelayanan Obat di Instalasi Farmasi Rawat Jalan Rumah Sakit
}

\section{Causes and Solutions for Waiting Time Duration on Drug Services of Hospital Outpatient Pharmacy Unit}

\author{
Nurul Fitriah, Nanditya Ika F, Satra Wiyanto \\ Program Studi Magister Manajemen Rumah Sakit Fakultas Kedokteran Universitas Brawijaya Malang
}

\begin{abstract}
ABSTRAK
Waktu tunggu pelayanan obat merupakan salah satu faktor yang mempengaruhi kepuasan pasien. Tahun 2013 kepuasan pasien terhadap waktu tunggu pelayanan obat di Instalasi Farmasi Rawat Jalan (IFRJ) Rumah Sakit X sebesar 57,7\%, menurun dari tahun sebelumnya yaitu $85 \%$. Berdasarkan hasil studi pendahuluan, diketahui bahwa rata-rata waktu tunggu pelayanan obat di IFRJ adalah 66 menit, lebih rendah dari Standar Pelayanan Minimum (SPM) yang ditetapkan. Hal ini mengindikasikan bahwa pelayanan obat di IFRJ belum maksimal. Tujuan dari penelitian ini adalah untuk mengidentifikasi faktor penyebab dan menemukan solusi atas permasalahan waktu tunggu pelayanan obat. Penelitian ini menggunakan pendekatan deskriptif dengan melakukan analisa alur pelayanan, observasi, wawancara, dan diskusi grup. Pencarian akar masalah dilakukan melalui Fokus Grup Diskusi (FGD) dengan peserta petugas IFRJ dan Manajer Penunjang Medis. Hasil penelitian menunjukkan adanya penumpukan resep pada petugas entri IFRJ. Hal tersebut disebabkan resep dokter belum sesuai dengan kebijakan obat RS, banyaknya obat racikan, petugas farmasi juga berperan sebagai customer service, dan kesulitan pemenuhan SDM. Berdasarkan daftar permasalahan tersebut dilakukan analisa " 5 Why" dan brainstrorming untuk menemukan akar masalah. Akar masalah yang ditemukan adalah komunikasi yang kurang efektif antara staf IFRJ dengan staf medis. Solusi yang disepakati yaitu membentuk tim untuk menjembatani komunikasi antara staf IFRJ dan staf medis. Terbentuknya tim ini diharapkan dapat memperbaiki komunikasi antara staf IFRJ dan staf medis sebagai upaya perbaikan waktu tunggu pelayanan obat di IFRJ.
\end{abstract}

Kata Kunci: Farmasi rawat jalan, waktu tunggu

\section{ABSTRACT}

Drug service waiting time is one of the factors that affect patient satisfaction. In 2013 patient satisfaction in waiting time for drug services at outpatient pharmacy unit of $X$ Hospital was $57,7 \%$, declining from previous year (85\%). Based on preliminary studies, the average waiting time for drug services of Outpatient Pharmacy $(O P)$ is 66 minutes, lower than the Minimum Service Standards (MSS). It indicates that drug services in OP were not yet maximized. This study aims to identify the causes and the solution of the problems. This study used a qualitative descriptive approach by analyzing service flow, observing, interviewing, and group discussion. Focus Group Discussion (FGD) that was attended by OP staffs and manager was done to find roots of the problem. The research showed that there was prescription accumulation on OP entry staff due to doctor's prescriptions did not match with hospital policies, the use of personalized medicine, pharmacy staff also functioned as customer service, as well as the problem in human resources. From the issues, " 5 Whys" analysis and brainstorming were done to find the root of the problem. The root of the problem found was ineffective communications between OP staffs and medical staffs. The solution was creating a team as a communication bridge between departments. This team is expected to bring more effective communications between OP staffs dan medical staffs as an effort to improve OP's waiting time drug services.

Keywords: Outpatient pharmacy, waiting time

Korespondensi: Nurul Fitriah. Program Studi Magister Manajemen Rumah Sakit Fakultas Kedokteran Universitas Brawijaya Malang, Jl. Veteran Malang Jawa Timur Tel.(0341)568989Email:nurulfitriah.dns@gmail.com 


\section{PENDAHULUAN}

Instalasi Farmasi merupakan bagian yang tidak dapat dipisahkan dari sistem pelayanan kesehatan rumah sakit yang utuh (1). Instalasi Farmasi rumah sakit merupakan unit di rumah sakit yang bertanggung jawab atas pengadaan dan penyajian informasi obat bagi seluruh pihak di rumah sakit (2). Tanggungjawab Instalasi Farmasi rumah sakit adalah mengembangkan pelayanan farmasi yang luas dan terkoordinir dengan baik untuk memenuhi kebutuhan rumah sakit secara menyeluruh serta memberikan pelayanan yang lebih baik pada pasien(1).

Waktu pelayanan yang baik berhubungan dengan kepuasan pelanggan, sehingga rumah sakit harus dapat mengontrol waktu pelayanan untuk mencapai kepuasan pasien (3). Standar waktu pelayanan di Instalasi Farmasi yang saat ini banyak dijadikan acuan adalah Standar Pelayanan Minimal (SPM) sesuai KMK No.129 Tahun 2008. Menurut SPM waktu tunggu pelayanan obat didefinisikan sebagai lamanya waktu yang diperlukan sejak pasien menyerahkan resep hingga pasien menerima obat. Standar waktu tunggu pelayanan obat dibagi menjadi dua, yaitu obat jadi dengan standar waktu maksimal 30 menit dan obat racikan dengan standar waktu maksimal 60 menit (4). Saat ini telah banyak rumah sakit menerapkan waktu tunggu pelayanan obat yang lebih pendek dari standar SPM untuk mewujudkan kepuasan pasien (5).

Rumah Sakit tempat studi merupakan rumah sakit umum tipe C, telah terakreditasi pada 16 bidang pelayanan pada tahun 2010 dan akan melaksanakan akreditasi KARS versi 2012. Pada tahun 2015, jumlah tempat tidur bertambah sebanyak $30 \%$ menjadi 155 , dengan rata-rata BOR $70 \%$ dan ALOS 4,7 hari. Tahun 2014 terjadi peningkatan jumlah kunjungan pasien rawat jalan secara signifikan, yaitu sebesar $199 \%$ dari tahun sebelumnya dengan tren yang terus meningkat pada tahun 2015. Peningkatan jumlah kunjungan tersebut berdampak langsung terhadap peningkatan jumlah pemeriksaan penunjang dan jumlah resep yang dilayani oleh Instalasi Farmasi Rawat Jalan (IFRJ).

Data Laporan tahunan rumah sakit tahun 2014 menyebutkan bahwa terdapat beberapa indikator mutu pelayanan Farmasi yang belum sesuai dengan SPM, antara lain waktu tunggu pelayanan obat yang belum diukur dan pencapaian kepuasan pasien $78 \%$, lebih rendah dibandingkan dengan standar minimal kepuasan pasien yaitu $\geq 80 \%$. Hasil survei kepuasan pasien tahun 2012 dan 2013 menunjukkan terjadi tren penurunan kepuasan pasien terhadap pelayanan IFRJ secara menyeluruh. Penurunan kepuasan secara signifikan terjadi pada poin waktu tunggu pelayanan obat di IFRJ, yaitu sebanyak $18,3 \%$ pada tahun 2013. Berdasarkan hasil survei, kepuasan terhadap waktu tunggu pelayanan obat menempati urut dua terbawah pada poin kepuasan pelayanan di IFRJ. Hal tersebut mengindikasikan waktu tunggu pelayanan obat di IFRJ belum maksimal.

Hasil evaluasi perhitungan waktu tunggu yang dilakukan oleh IFRJ pada bulan Juli dan Agustus 2015 diketahui bahwa waktu tunggu pelayanan obat yang dibutuhkan rata-rata sebesar 68 menit pada saat jam sibuk. Hasil studi pendahuluan terhadap waktu tunggu pelayanan obat di IFRJ pada bulan September 2015 juga memberikan hasil yang tidak jauh berbeda, yaitu rata-rata dibutuhkan waktu 66 menit pada saat jam sibuk. Waktu tunggu pelayanan obat tersebut belum sesuai dengan standar SPM, yaitu maksimal 60 menit untuk obat racikan dan maksimal 40 menit untuk obat jadi.

Waktu tunggu merupakan aspek kepuasan yang penting karena motivasi yang mempengaruhi pelanggan dalam memilih pelayanan antara lain adalah waktu tunggu dan kenyaman pelayanan (6). Kepuasan pelayanan farmasi bersifat multi dimensi, meliputi 1) sikap petugas farmasi; 2) pemberian informasi obat; 3) ketersediaan obat; 4) Fasilitas; 5) lokasi; 6) waktu tunggu pelayanan obat; dan 7) harga obat (7). Penelitian Khudair dan Raza menemukan bahwa kepuasan pasien terhadap layanan farmasi dipengaruhi oleh kecepatan pelayanan, sikap petugas, konseling obat, dan lokasi (6). Afolabi dan Erhun dalam penelitiannya menemukan bahwa terdapat hubungan yang erat antara kepuasan waktu tunggu pelayanan obat dengan kepuasan pasien terhadap pelayanan farmasi. Kepuasan berpengaruh terhadap loyalitas pasien terhadap pelayanan tersebut, sehingga diperlukan perbaikan waktu tunggu pelayanan obat di IFRJ untuk meningkatkan kepuasan pasien(8).

Lamanya waktu tunggu pelayanan obat di instalasi farmasi dapat disebabkan oleh beberapa faktor antara lain yaitu komponen delay. Komponen delay disebabkan karena petugas mengerjakan kegiatan lain atau mengerjakan resep sebelumnya. Total waktu komponen delay dapat lebih besar dari total waktu komponen tindakan. Faktor lain adalah obat sering kosong sehingga membutuhkan waktu untuk mengambil obat, program komputer belum sempurna, SDM belum terampil dan cekatan; serta prosedur belum dikerjakan dengan maksimal. Kombinasi faktor-faktor tersebut menyebabkan lamanya waktu tunggu pelayanan obat (5).

Tujuan penelitian ini adalah untuk mengidentifikasi faktorfaktor penyebab lamanya waktu tunggu pelayanan obat di IFRJ Rumah Sakit, menentukan alternatif solusi, dan memberikan rekomendasi atas permasalahan waktu tunggu pelayanan obat. Dengan adanya penelitian ini diharapkan dapat memperbaiki waktu tunggu pelayanan obat di IFRJ sehingga dapat memenuhi SPM serta untuk meningkatkan kepuasan pasien terhadap waktu tunggu pelayanan obat.

\section{METODE}

Penelitian ini dilakukan dengan pendekatan deskriptif, yang diawali dengan melakukan studi pendahuluan berupa obervasi dan pengukuran waktu tunggu pelayanan obat di IFRJ Rumah Sakit. Observasi pelayanan dilakukan selama jam pelayanan IFRJ pada resep yang dipilih secara acak. Berdasarkan hasil observasi tersebut, dilakukan analisa alur dengan mencatat kegiatan dan waktu yang dibutuhkan pada setiap kegiatan yang dilakukan terutama pada jam-jam sibuk. Studi pendahuluan dan analisa alur dilakukan selama kurang lebih 2 minggu. Setelah mendapatkan gambaran faktor-faktor yang dapat mempengaruhi lamanya waktu tunggu pelayanan obat di IFRJ, dilakukan Fokus Grup Diskusi (FGD) yang bertujuan untuk mencari faktor-faktor yang paling berpengaruh terhadap lama pelayanan tersebut. Kegiatan FGD melibatkan 9 staf IFRJ yang terdiri dari 2 apoteker, 3 tenaga teknis kefarmasian (TTK), 2 penanggung jawab shift dan 2 koordinator serta manajer penunjang medis. Selanjutnya dilakukan analisa "5 Why" dan brainstorming untuk menemukan akar permasalahan. Setelah ditemukan akar masalah maka dilanjutkan dengan pemilihan alternatif solusi melalui studi literatur untuk mendukung perencanaan penerapan solusi. Pencarian alternatif solusi ini selain melibatkan staf IFRJ dan manajer penunjang medis juga melibatkan Kepala Instalasi Rawat Jalan. Untuk dapat mengoptimalkan komunikasi antara IFRJ dan Instalasi Rawat Jalan khususnya dengan staf medis, 
diperlukan adanya jembatan komunikasi. Jembatan komunikasi yang dimaksud adalah tim yang terdiri dari staf medis dan staf IFRJ yang mempunyai kewenangan untuk melakukan intervensi atau mengusulkan perubahan terhadap kebijakan baik di IFRJ maupun di Instalasi Rawat Jalan sesuai dengan analisa kebutuhan.Untuk menentukan prioritas solusi digunakan metode Urgency, Seriousness, dan Growth (USG) dengan skala 1-5, sehingga solusi terpilih dapat segera diaplikasikan dan sesuai dengan kebutuhan rumah sakit.

\section{HASIL}

Gambaran Alur, Proses, dan Waktu Tunggu Pelayanan Farmasi Rawat Jalan

Setelah dilakukan analisa alur didapatkan permasalahan yaitu menumpuknya resep pada petugas entri Instalasi Farmasi Rawat Jalan (IFRJ). Sejak pasien meletakkan resep hingga proses entri dilakukan dibutuhkan waktu rata-rata 20 menit pada saat jam sibuk, sedangkan proses entri resep sendiri untuk satu resep rata-rata membutuhkan waktu 2 menit. Lamanya proses entri data disebabkan karena petugas entri juga membantu menyerahkan obat, mempersiapkan, dan melakukan pengemasan obat pada jam-jam sibuk. Selain itu petugas entri juga melakukan konfirmasi hasil telaah resep kepada staf medis rawat jalan (dokter); menjawab pertanyaan dan memberikan penjelasan kepada pasien yang pengambilan obatnya membutuhkan persyaratan khusus; melakukan penyesuaian resep agar sesuai dengan plafon Indonesia Case Base Group's (INA CBG's); dan mengkomunikasikan hasil penyesuaian resep kepada staf medis rawat jalan. Khusus pada pasien JKN entri data dilakukan dua kali, karena selain elektronik resep (e-resep) dibutuhkan resep manual untuk keperluan klaim INA CBG's. Pada proses persiapan terdapat kendala petugas belum hafal letak obat; obat habis stok; dan banyaknya resep dan jenis obat racikan. Pada proses penyerahan obat terdapat kendala petugas membutuhkan waktu yang lama untuk memberikan komunikasi informasi edukasi (KIE). Hasil analisa alur dapat dilihat pada Gambar 1.

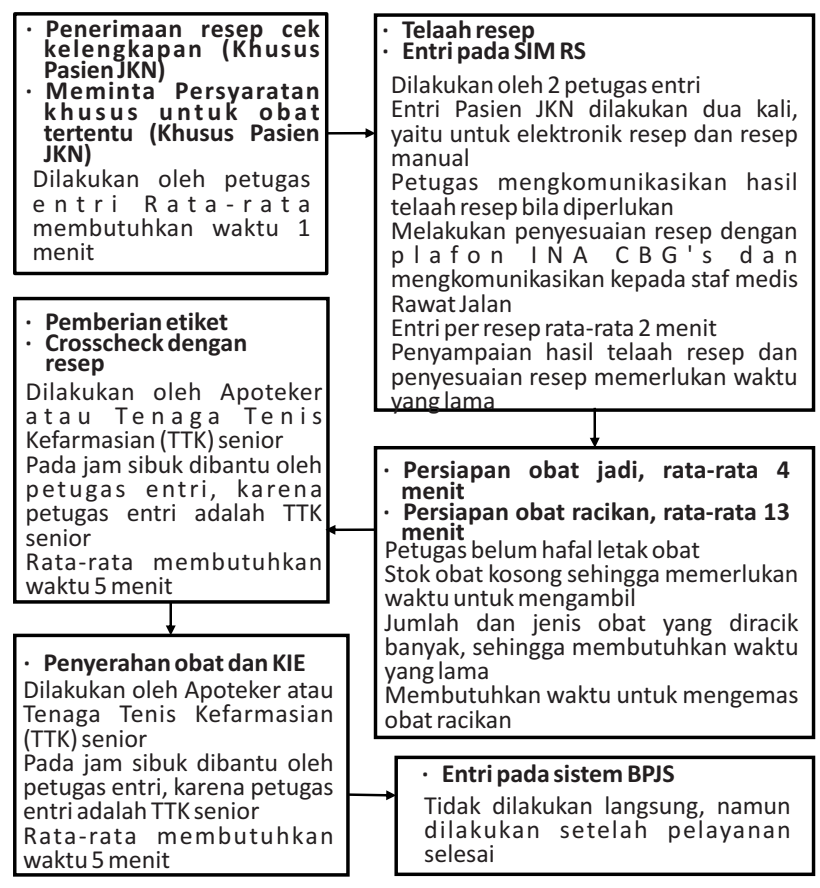

Gambar 1. Analisa alur pelayanan instalasi farmasi rawat jalan
Petugas entri resep terdiri dari dua petugas saat jam sibuk, yaitu petugas yang melayani pasien dengan resep peserta Jaminan Kesehatan Nasional (JKN) dan petugas yang melayani resep pasien umum serta asuransi rekanan. Meskipun demikian pada pelaksanaannya petugas entri resep bagi pasien umum juga melakukan entri resep pasien JKN karena banyaknya jumlah resep pasien JKN dibandingkan jumlah resep pasien umum dan asuransi rekanan. Jumlah resep pasien JKN di IFRJ lebih banyak dibandingkan dengan jumlah resep pasien umum dan asuransi rekanan dengan perbandingan hampir dua kali lipat (Tabel 1).

Tabel 1. Rekapitulasi jumlah resep di IFRJ bulan Mei - Juni 2015

\begin{tabular}{lcc}
\hline Bulan & $\begin{array}{c}\text { Asuransi lain, dan tidak } \\
\text { terasurani }\end{array}$ & JKN \\
\hline Mei & 3949 & 5612 \\
Juni & 4015 & 5966 \\
Juli & 3178 & 5149 \\
\hline
\end{tabular}

Sumber: Instalasi Farmasi Rumah Sakit X

Banyaknya resep pasien JKN menyebabkan proses entri harus dilakukan oleh petugas khusus, karena mekanisme yang berbeda dengan resep pasien umum. Pada proses entri resep pasien JKN selain dilakukan telaah resep juga dilakukan penyesuaian resep dengan plafon INA-CBG's. Penyesuaian dilakukan terutama untuk obat-obatan yang tidak ada dalam Formularium Nasional (Fornas). Proses entri resep baik pada resep pasien JKN dan umum hanya dapat dilakukan oleh staf senior, sebab selain melakukan telaah resep, petugas entri juga wajib menyampaikan hasil telaah resep yang tidak sesuai secara langsung ke staf medis (Dokter) Instalasi Rawat Jalan untuk mendapat persetujuan obat pengganti.

Terdapat beberapa hambatan operasional yang mempengaruhi kecepatan pelayanan obat di IFRJ, antara lain yaitu sumber daya manusia (SDM). Sumber daya manusia yang dimiliki oleh Instalasi Farmasi Rumah Sakit $X$ terdiri atas 4 apoteker, 20 TTK, dan 1 administrasi. Sumber Daya Manusia di IFRJ sendiri terdiri atas 2 Apoteker dan 10 TTK. Tenaga tersebut terbagi menjadi 3 shift, yaitu shift pagi (07.00-14.00), shift sore (14.00-21.00) dan shift malam (21.00-01.00). Masing-masing shift terdiri dari 4 TTK dan 1 apoteker kecuali untuk shift malam yang hanya terdiri dari 1 orang TTK. Selain itu TTK di IFRJ mempunyai tugas ganda untuk membantu Instalasi Farmasi Rawat Inap demikian juga sebaliknya, hal ini disebabkan kurangnya TTK yang dimiliki oleh rumah sakit akibat sulitnya pemenuhan TTK itu sendiri.

Hambatan lain yaitu banyaknya obat racikan. Banyaknya resep obat racikan membuat tahap persiapan obat memerlukan waktu lama, sehingga petugas entri juga membantu mengerjakan persiapan obat dan penyerahan obat kepada pasien terutama pada jam sibuk. Hal ini menyebabkan proses persiapan obat berjalan cepat namun juga menyebabkan resep menumpuk di bagian entri. Hambatan operasional lain yaitu petugas entri juga berperan sebagai customer service dengan memberikan informasi kepada pasien yang tidak membawa kelengkapan untuk pengambilan jenis obat tertentu. Hal 
ini disebabkan informasi yang diberikan kurang jelas baik dari petugas pendaftaran, perawat rawat jalan maupun dokter. Selain menghambat proses di IFRJ hal ini juga menyebabkan pasien tidak mendapatkan obat sesuai dengan yang dibutuhkan.

Resep elektronik menjadi salah satu hambatan operasional. Hal ini terjadi karena dokter harus menggunakan dua jenis resep yaitu elektronik dan manual, khususnya pada pasien JKN. Resep manual digunakan untuk melakukan klaim ke Badan Penyelenggara Jaminan Sosial Kesehatan (BPJS-K). Hal tersebut selain memberatkan pihak dokter, juga memberatkan pihak farmasi karena harus melakukan dua kali entri data untuk satu pasien. Sebagai akibatnya, dokter cenderung untuk tidak menggunakan resep elektronik, sehingga penggunaan resep elektronik tidak berjalan maksimal. Selain itu masih banyak resep dokter yang tidak sesuai dengan Fornas, baik jenis maupun harga obat. Khusus bagi resep dengan harga di luar ketentuan Fornas, petugas entri harus melakukan penyesuaian jumlah obat agar sesuai dengan batas penggantian INA CBG's. Penggantian jumlah obat ini akan dilaporkan oleh petugas entri kepada dokter penanggung jawab pasien untuk mendapat persetujuan. Sehingga hal ini menyebabkan proses entri di IFRJ berjalan lebih lambat.

Jam praktek dokter di Instalasi Rawat Jalan telah diatur agar pasien tidak menumpuk di satu waktu. Dalam kenyataannya jam praktek dokter tidak sesuai dengan jam yang telah ditentukan karena berbagai kendala teknis seperti visite pasien rawat inap, ada operasi, dan lain sebagainya. Kondisi tersebut menyebabkan penumpukan pasien terjadi pada satu waktu, yaitu pagi pada jam 9 hingga 11 dan sore pada jam 5 hingga 8 malam. Hal ini juga menyebabkan terjadinya penumpukan resep pasien di IFRJ.

\section{Akar Penyebab Masalah}

Berdasarkan hasil observasi dan analisa pada alur pelayanan di IFRJ, ditemukan bahwa masalah utama dari lamanya waktu tunggu pelayanan obat adalah terjadinya penumpukan resep di bagian entri IFRJ. Untuk mencari faktor-faktor yang menyebabkan terjadinya penumpukan resep di bagian entri IFRJ dilakukan Fokus Grup Diskusi (FGD) menggunakan bantuan diagram Ishikawa (Fishbone). Setelah menemukan permasalahan pada sirip ikan, dilanjutkan dengan melakukan analisa "5 Why" untuk menemukan akar permasalahan. Fokus grup diskusi melibatkan 9 staf IFRJ yang terdiri dari 2 Apoteker, 3 Tenaga Teknis Kefarmasian (TTK), 2 penanggung jawab shift dan 2 koordinator serta Manajer Penunjang Medis. Hasil dari analisa "5 Why" disajikan pada Tabel 2.
Hasil analisa "5 Why" menemukan bahwa dari faktor man masalah yang ditemukan yaitu tidak ada petugas khusus yang menangani permasalahan. Pada faktor methode dan material terdapat masalah yaitu kurangnya waktu untuk berkomunikasi, sedangkan faktor management terdapat masalah yaitu tidak ada petugas khusus yang memiliki kewenangan komunikasi antar bagian. Berdasarkan daftar permasalahan tersebut dilakukan brainstrorming untuk merumuskan akar masalah. Hasil proses brainstorming ditemukan dua akar permasalahan, yaitu sulitnya pemenuhan SDM dan komunikasi yang kurang efektif antara staf IFRJ dengan staf medis (dokter) di Instalasi Rawat Jalan, khususnya pada pasien JKN. Setelah ditemukan akar masalah, brainstorming dilanjutkan untuk menentukan prioritas masalah. Berdasarkan hasil brainstorming disepakati bahwa masalah yang terpilih sebagai prioritas adalah kurang efektifnya komunikasi antara IFRJ dengan staf medis Instalasi Rawat Jalan khususnya pada pasien JKN.

\section{AlternatifSolusi}

Berdasarkan prioritas masalah dilakukan analisis alternatif solusi yang paling dibutuhkan saat ini dan paling memungkinkan untuk diterapkan oleh rumah sakit melalui proses brainstorming dan studi literatur yang dilakukan. Solusi yang pertama adalah optimalisasi Tim Farmasi dan Terapi Rumah Sakit (TFT). Rumah Sakit X telah memiliki Tim Farmasi dan Terapi (TFT), hanya saja belum berfungsi maksimal, karena ketua dan anggota TFT bukan merupakan dokter tetap di rumah sakit. Merujuk pada Peraturan Menteri Kesehatan No. 58 Tahun 2014 tentang standar pelayanan kefarmasian di rumah sakit, TFT terdiri dari dokter dan apoteker (9). Tim tersebut memiliki kewenangan antara lain mengembangkan kebijakan penggunaan obat, mengembangkan standar terapi, melakukan intervensi dalam meningkatkan penggunaan obat yang rasional, dan menyebarluaskan informasi terkait kebijakan penggunaan obat di rumah sakit. Solusi kedua adalah membentuk Tim Kendali Farmasi JKN. Tim ini direncanakan terdiri dari dokter dan apoteker dengan persyaratan bahwa dokter dan apoteker yang terlibat adalah dokter tetap rumah sakit, memiliki pengetahuan tentang JKN dan kondisi rumah sakit, serta memiliki keterampilan komunikasi dan analisa yang baik. Kewenangan tim ini mengadopsi dari kewenangan TFT namun mengkhususkan diri pada permasalahan farmasi bagi pasien JKN, mengingat banyaknya kunjungan pasien JKN dan banyaknya masalah pada penanganan pasien JKN di di rumah sakit tempat studi. Dengan menggunakan metode USG ditetapkan pembentukan tim kendali farmasi sebagai prioritas solusi.

Tabel 2. Rumusan akar masalah berdasarkan analisa " 5 Why"

\begin{tabular}{|c|c|c|c|c|c|c|c|}
\hline No & Faktor & Masalah & Why I & Why II & Why III & Why IV & Why V \\
\hline \multirow[t]{2}{*}{1} & Man & $\begin{array}{l}\text { SDM IFRJ dan } \\
\text { IFRN belum } \\
\text { dipisahkan }\end{array}$ & $\begin{array}{l}\text { Bila dipisah } \\
\text { terasa kurang }\end{array}$ & SDM Kurang & $\begin{array}{l}\text { Pemenuhan } \\
\text { SDM sulit }\end{array}$ & - & - \\
\hline & & $\begin{array}{lr}\text { Dokter } & \text { Praktek } \\
\text { belum } & \text { sesuai } \\
\text { jadwal } & \end{array}$ & $\begin{array}{l}\text { Ada Visite, OP, } \\
\text { dan lain-lain }\end{array}$ & $\begin{array}{l}\text { Sudah } \\
\text { disampaikan } \\
\text { kepada IRJ } \\
\text { namun belum } \\
\text { ada tindak } \\
\text { lanjut }\end{array}$ & $\begin{array}{l}\text { Komunikasi } \\
\text { kurang intens }\end{array}$ & $\begin{array}{l}\text { Komunikasi } \\
\text { dilakukan oleh } \\
\text { sesama } \\
\text { manajer } \\
\text { saat rapat pleno } \\
\text { saja }\end{array}$ & $\begin{array}{l}\text { Tidak ada } \\
\text { petugas khusus } \\
\text { yang } \\
\text { menangani } \\
\text { masalah ini }\end{array}$ \\
\hline
\end{tabular}


Tabel 2. Rumusan akar masalah berdasarkan analisa " 5 Why"

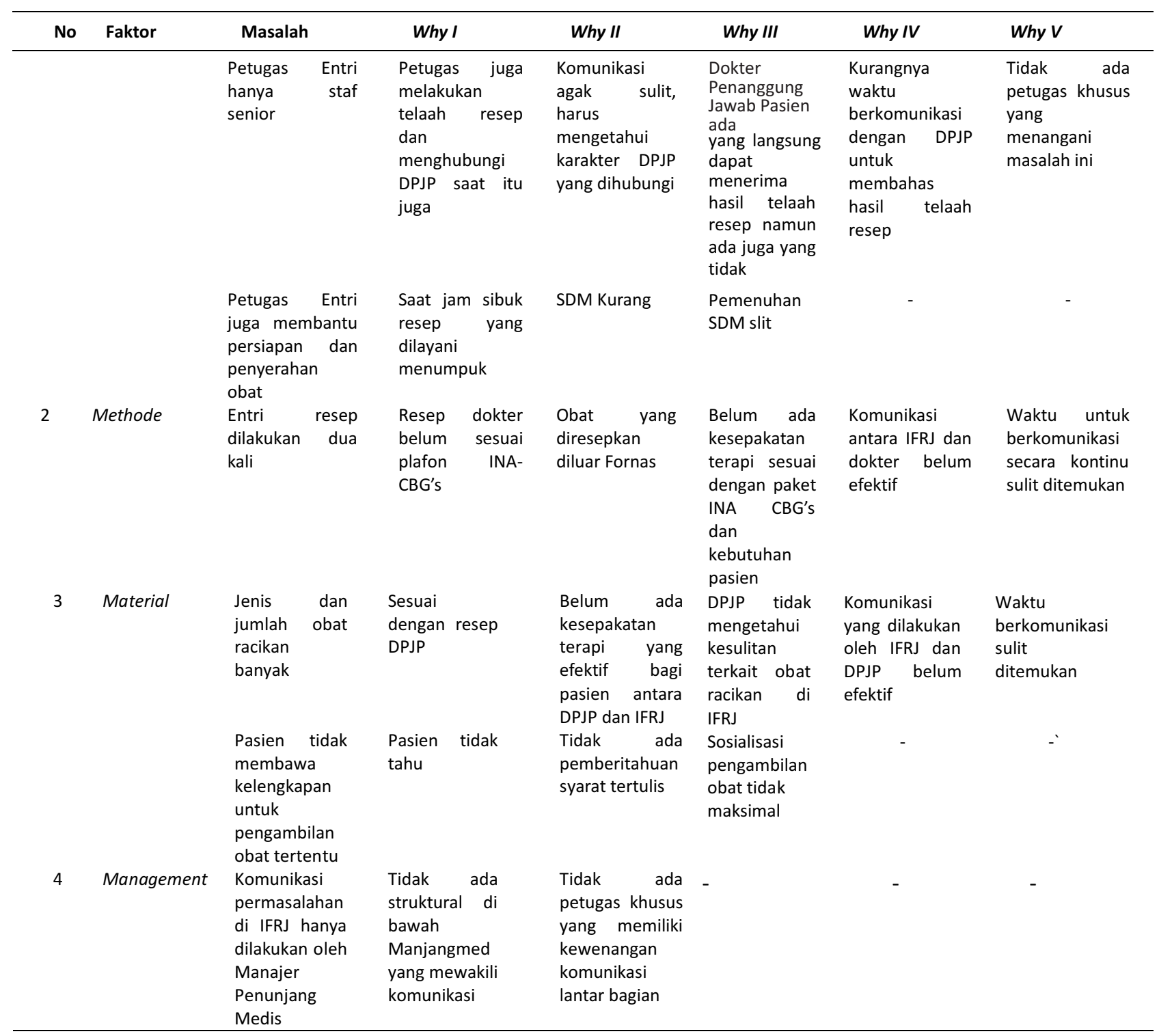

Tabel 3. Pemilihan alternatif solusi dengan metode USG

\begin{tabular}{|c|c|c|c|c|c|c|}
\hline \multirow[b]{2}{*}{ No } & \multirow{2}{*}{$\begin{array}{l}\text { Alternatif } \\
\text { Solusi }\end{array}$} & \multicolumn{3}{|c|}{ Nilai } & \multirow{2}{*}{$\begin{array}{l}\text { Total } \\
\text { Nilai }\end{array}$} & \multirow{2}{*}{ Rangking } \\
\hline & & $\begin{array}{c}\text { Urgency } \\
(1-5)\end{array}$ & $\begin{array}{c}\text { Seriousness } \\
(1-5)\end{array}$ & $\begin{array}{c}\text { Growth } \\
(1-5)\end{array}$ & & \\
\hline 1 & $\begin{array}{l}\text { Optimalisasi } \\
\text { TFT }\end{array}$ & 2 & 4 & 4 & 24 & II \\
\hline 2 & $\begin{array}{l}\text { Membentuk } \\
\text { Tim } \\
\text { Kendali } \\
\text { Farmasi JKN }\end{array}$ & 5 & 5 & 4 & 60 & I \\
\hline
\end{tabular}

\section{DISKUSI}

Kepuasan terhadap pelayanan farmasi bersifat multidimensi (7). Lamanya waktu tunggu pelayanan di Instalasi Farmasi Rawat Jalan merupakan salah satu aspek penting yang mempengaruhi kepuasan pasien. Waktu tunggu mempunyai 4 dimensi yaitu objektif (actual waiting time), subjektif atau persepsi (estimasi lama menunggu), kognitif (evaluasi proses menunggu), afektif (respon terhadap proses menunggu). Kepuasan yang terkait waktu tunggu dapat dipengaruhi expected waiting time (EWT), perceived waiting time (PWT), actual waiting time (AWT) dan disconfirmation $(10,11)$. Walaupun penilaian terhadap proses menunggu lebih banyak dipengaruhi oleh dimensi subjektif (1), namun penurunan waktu tunggu yang sesungguhnya mencerminkan kualitas pelayanan yang diberikan oleh instalasi farmasi.

Berdasarkan hasil observasi ditemukan bahwa penyebab lama waktu tunggu pelayanan obat di IFRJ Rumah Sakit X adalah penumpukan resep pada petugas entri. Hal ini sejalan dengan yang dikemukakan oleh Yulianthi bahwa adanya komponen delay menyebabkan proses menjadi lebih lama. Delay disebabkan antara lain karena petugas belum mengerjakan resep karena mengerjakan pekerjaan lain atau mengerjakan resep sebelumnya (5). Hasil analisa "5 Why" diketahui bahwa dari faktor man ditemukan masalah tidak ada petugas khusus yang menangani permasalahan. Pada faktor methode dan material terdapat masalah yaitu kurangnya waktu untuk berkomunikasi. Sedangkan pada faktor management terdapat masalah yaitu tidak ada petugas khusus yang memiliki kewenangan komunikasi antar bagian. Apabila dicermati masalahmasalah tersebut sebagian besar berkaitan dengan 
sumber daya manusia, sesuai dengan hasil penelitian di Sahlgrenska University yang menemukan bahwa faktor manusia memang memegang peranan yang paling penting. Namun apabila pemecahan masalah yang dilakukan adalah dengan menambah jumlah SDM, maka hal ini bukan pilihan dimasa depan, karena perkembangan teknologi mengarah pada penurunan jumlah SDM yang dibutuhkan (12). Sehingga perlu dirumuskan alternatif solusi selain menambah jumlah SDM.

Hasil proses brainstorming ditemukan dua akar permasalahan, yaitu sulitnya pemenuhan SDM dan komunikasi yang kurang efektif antara staf IFRJ dengan staf medis (dokter) di Instalasi Rawat Jalan, khususnya pada pasien JKN. Berdasarkan hasil brainstorming lanjutan disepakati bahwa masalah yang terpilih sebagai prioritas adalah kurang efektifnya komunikasi antara IFRJ dengan staf medis Instalasi Rawat Jalan khususnya pada pasien JKN. Sebagai contoh kurangnya komunikasi antara bagian IFRJ dengan staf medis IRJ adalah mengenai peresepan obat pasien JKN. Staf medis (dokter) menulis resep tidak sesuai Fornas, akibatnya petugas IFRJ harus menambah waktu pelayanan resep pasien dengan menanyakan dan menyesuaikan kembali resep sesuai fornas atau sesuai plafon INA CBG's. Hal ini memperpanjang waktu tunggu pelayanan obat di IFRJ. Kurang efektifnya komunikasi mengakibatkan kerja sama tim tidak maksimal. Menurut Megawati faktor penyebab potensial yang mungkin mempengaruhi kecepatan pelayanan adalah kerjasama tim secara konsisten belum menjadi budaya organisasi di rumah sakit (7). Petugas kesehatan harus saling bekerjasama untuk memecahkan masalah kesehatan yang kompleks, namun terkadang semangat kerjasama tersebut tidak tampak. Hal ini dapat disebabkan karena lemahnya komunikasi antar petugas kesehatan. Lemahnya komunikasi dapat mempengaruhi kualitas pelayanan yang diberikan yang pada akhirnya akan menimbulkan kerugian bagi pasien dan keluarganya (13).

Komunikasi dalam dunia kesehatan merupakan perpaduan antara seni dan ilmu, yaitu penerapan metodologi komunikasi kesehatan ilmiah serta sistematis (14). Komunikasi dalam organisasi kesehatan dapat berupa tulisan dan/atau komunikasi verbal dan nonverbal. Bentuk komunikasi tertulis antara lain rekam medik, resep, standar prosedur operasional, dan surat edaran. Komunikasi verbal dan non-verbal dapat terjadi dalam berbagai bentuk misalnya komunikasi interpersonal yang melibatkan dua atau beberapa orang serta pertemuan yang melibatkan banyak orang. Pada komunikasi interpersonal komunikasi verbal dan nonverbal digunakan baik secara tunggal maupun sebagai pendukung dari komunikasi tulisan yang telah dilakukan (13).

\section{DAFTAR PUSTAKA}

1. Purwanto H, Indiati, dan Hidayat T. Faktor Penyebab Waktu Tunggu Lama di Pelayanan Instalasi Farmasi Rawat Jalan RSUD Blambang. Jurnal Kedokteran Brawijaya. 2015; 28(2): 159-162.

2. Karman J, Hakim L, dan Irbantoro D. Pengaruh Perubahan Alur terhadap Waktu Pelayanan Farmasi Pasien Pulang Rawat Inap RS Baptis Batu. Jurnal Kedokteran Brawijaya. 2015; 28(2): 153-158.
Hasil brainstorming dalam menentukan alternatif solusi permasalahan adalah membentuk Tim Kendali Farmasi JKN. Tim ini diharapkan dapat berfungsi sebagai jembatan komunikasi antara staf IFRJ dan staf medis IRJ. Dengan adanya tim ini diharapkan agar petugas IFRJ dapat fokus menjalankan tugas kefarmasian. Kriteria Tim kendali farmasi JKN adalah sebagai berikut: diketuai oleh seorang dokter, beranggotakan dokter dan/atau apoteker yang memiliki pengetahuan tentang farmasi dan kebijakan pasien peserta JKN di rumah sakit, serta memiliki teknik berkomunikasi yang baik.

Kewenangan Tim Kendali Farmasi JKN mengacu pada kewenangan Tim Farmasi dan terapi rumah sakit, namun dengan memfokuskan pada permasalahan pasien JKN. Kewenangan Tim Kendali Farmasi JKN antara lain yaitu: mengembangkan kebijakan penggunaan obat JKN, mengembangkan standar terapi yang disesuaikan plafon INA CBG's, melakukan intervensi dalam meningkatkan penggunaan obat yang rasional, dan menyebarluaskan informasi terkait kebijakan penggunaan obat JKN di rumah sakit. Ketua tim mempunyai tugas berkomunikasi dengan Staf medis IRJ untuk mencapai tujuan bersama, yaitu pelayanan kesehatan bermutu, berorientasi pada keamanan dan kebutuhan pasien, efektivitas tindakan, dan efisiensi biaya; berkoordinasi dengan Manajer Pelayanan Medis, Manajer Penunjang Medis, dan Kepala Instalasi Rawat Jalan. Anggota tim mempunyai tanggung jawab melakukan konversi obat di luar Fornas, mengatur jumlah obat sesuai paket INA CBG's dan evaluasi penggunaan obat di IFRJ. Kinerja tim akan dievaluasi secara berkala untuk mengetahui pengaruh tim terhadap lama waktu tunggu pelayanan obat di IFRJ.

Waktu tunggu pelayanan obat di IFRJ Rumah Sakit ini belum memenuhi standar SPM. Akibatnya kepuasan pasien terhadap waktu tunggu pelayanan obat rendah. Hasil observasi ditemukan bahwa terjadi penumpukan resep pada bagian entri. Setelah dilakukan FGD dan brainstorming, ditarik kesimpulan bahwa prioritas masalah terletak pada kurang efektifnya komunikasi antara IFRJ dan staf Edi IRJ. Sehingga perlu dibentuk jembatan komunikasi, dalam hal ini berbentuk tim. Kinerja tim akan dievaluasi secara berkala. Apabila hasil kerja tim tidak berpengaruh signifikan terhadap penurunan waktu tunggu pelayanan obat di IFRJ, maka perlu dikaji ulang faktor yang mempengaruhi kecepatan pelayanan obat di IFRJ. Salah satu faktor penentu waktu tunggu pelayanan obat adalah jumlah petugas, namun terdapat strategi mempersingkat waktu pelayanan obat tanpa menambah jumlah petugas, yaitu dengan menerapkan strategi perubahan dan penyesuaian alur pelayanan obat (15). Hal tersebut belum dilakukan pada penelitian ini, sehingga membuka peluang bagi penelitian selanjutnya untuk melakukan intervensi tersebut.

3. Otani K, Herrmann PA, and Kurz RS. Improving Patient satisfaction in Hospital Care Settings. Health Services Management Research. 2011; 24(4): 163-169.

4. Departemen Kesehatan Republik Indonesia. Standar Pelayanan Minimum Rumah Sakit. Jakarta: Departemen Kesehatan RI; 2008.

5. Yulianthy. Analisis Waktu Tunggu Pelayanan Resep Pasien Umum di Farmasi Unit Rawat Jalan Selatan Pelayanan Kesehatan Sint Carolus Tahun 2011. [Tesis]. 
Universitas Indonesia, Jakarta. 2012.

6. Khudair IF and Raza S. Measuring Patients Satisfaction with Pharmaceutical Services at Public Hospital in Qatar. International Journal of Health Care Quality Assurance. 2013; 26(5): 398-419.

7. Megawati, Hakim L, dan Irbantoro D. Penurunan Waktu Tunggu Pelayanan Obat Rawat Jalan Instalasi Farmasi Rumah Sakit Baptis Batu. Jurnal Kedokteran Brawijaya. 2015; 28(2): 163-168.

8. Afolabi $\mathrm{MO}$ and Erhun WO. Patient Response to Waiting Time in An Out-patient Pharmacy in Nigeria. Tropical Journal of Pharmaceuticah Research. 2003; 2(2): 207-214.

9. Menteri Kesehatan Republik Indonesia. PMK: 58 Tahun 2014 tentang Standar Pelayanan Kefarmasian di Rumah Sakit. Jakarta: Kementrian Kesehatan RI; 2014.

10. Pruyn A and Smidts A. Effects of Waiting on the Satisfaction with the Service: Beyond Objective Time Measures. International Journal of Research in
Marketing. 1998;15(4): 321-334.

11. Davis $\mathrm{MM}$ and Heineke J. How Disconfirmation Perception and Actual Waiting Times Impact Customer Satisfaction. International Journal of Service Industry Management. 1998; 9(1): 64-73.

12. Chou YC, Chen BY, Tang YY, et al. Prescription-Filling Process Reengineering of an Outpatient Pharmacy. Journal of Medical Systems. 2012; 36(2): 893-902.

13. Faqin C. Collaboration between Nurses and Physician: No Longer A Choice. Academic Medicine: Journal of The Association of American Medical Colleges. 1992; 67(5): 295-303.

14. Hadjan MNR. Efektivitas Pelayanan Prima Sebagai Upaya Meningkatkan Pelayanan di Rumah Sakit (Perspektif Psikologi). Jurnal Psikologi. 2001; 2(10): 105-115.

15. Eriksson H, Bergbrant IM, Berrum I, and Mörck B. Reducing Queues: Demand and Capacity Variations. International Journal of Health Care Quality Assurance. 2011; 24(8): 592-600. 